\title{
An Intergenerational Study of Hupa Stress*
}

\author{
MATTHEW GORDON and EDMUNDO LUNA \\ University of California, Santa Barbara
}

\section{Introduction}

Among Edward Sapir's greatest contributions to the study of American Indian languages is the body of Hupa texts he transcribed during the summer of 1927. Recently compiled and analyzed in a published volume edited by Victor Golla and Sean O'Neill (2001), Sapir's field notes mark stress, which has been relatively understudied in Hupa and more generally Pacific Coast Athabaskan. Aside from brief descriptions of stress and prosody in Woodward (1964) and Golla (1970) and a small phonetic study of tone by Goddard (1928), there are to the best of our knowledge no published analyses of Hupa prominence. This paper compares the Hupa stress patterns transcribed by Sapir with results of a study of stress based on spoken data recorded almost 70 years later at a time when the language continued to be spoken fluently by fewer than a dozen speakers.

\section{Previous Descriptions of Hupa Stress}

There is little previous work on Hupa stress. Woodward (1964:199) briefly comments on the stress system, stating "usually the long syllable (CVY or CVCC where the final cluster involves neither $/ \mathrm{l} /$ nor $/ \mathrm{h} /$ ) of a polysyllabic word receives a primary stress." She further remarks, "when a polysyllabic word consists entirely of short syllables, there is a tendency to place a somewhat heavier stress on the penult." Golla (1970:40-41) also reports a weight effect, suggesting "long vowels are more highly stressed than adjacent short vowels with the long vowel of a closed syllable most highly stressed." He also alludes to a declination effect spanning a sentence such that the "first syllables of a sentence are more prominent in stress and higher pitch than those that follow."

\footnotetext{
* Many thanks are due to Victor Golla and Danny Ammon for their helpful logistical advice and suggestions. A great debt of gratitude is owed to the speakers of Hupa for teaching me about their language. Thanks to the American Philosophical Society for making available a microfilm copy of Edward Sapir's 1927 field notes on Hupa and to Sean O'Neill for supplying an electronic version of the Hupa texts. Thanks also to the audience at the 2002 SSILA meeting in San Francisco and BLS for comments. Any errors are solely the authors' responsibility.
} 
Matthew Gordon and Edmundo Luna

Both Woodward and Golla point to the greater weight of long vowels relative to other syllables and also suggest some role for consonants in the weight system albeit in different capacities. Golla's description suggests an overall declination effect that presumably makes earlier syllables more stressed than lighter syllables, whereas Woodward states that the penult is the default location of stress.

\section{An Analysis of Stress in Sapir's Hupa Texts \\ 2.1. Methodology}

For the first part of the present study, stress patterns were analyzed for 18 of the 77 stories transcribed by Sapir. Of the 18 stories examined here, nine were narrated by Sam Brown, three by Emma Frank, five by Jake Hostler, and one by John Shoemaker. Throughout the texts, Sapir marked stress with an acute accent mark. The vast majority of words are marked with a single stress mark, though there are some that have no stress mark, or, in rare instances, have multiple stress marks. ${ }^{1}$ This paper is based on all words with a single stress mark in the examined stories.

The location of stress was tracked according to several factors and entered into a database. First, distance of the stress from both the left edge and the right edge of the word was tracked, in order to ascertain whether stress tended to fall a fixed distance from the word edge. Second, the internal structure of the stressed syllable, i.e., open vs. closed, long vowel vs. short vowel, and the structure of other syllables in the word were examined in order to determine whether stress was sensitive to syllable weight in Hupa. Third, morphological structure was also evaluated in order to assess potential preferences for stressing roots over affixes or vice versa, a phenomenon found elsewhere in Athabaskan (see section 4.2).

In cases where a single word with the same pattern appeared multiple times within the same story, only one token was counted toward the tabulation of stress patterns. This was done in order to avoid biasing the study toward stress patterns found in very frequent words. If, however, the same word displayed different stress patterns within the same story, each variant pattern counted toward the tabulations in proportion to its frequency relative to other variant patterns. Thus, for example, if a word appeared three times in the same text, once with initial stress and twice with second syllable stress, the initial stress pattern contributed 0.33 to the sum total of words with initial stress, while the second syllable stress pattern counted 0.67 toward the total for words with peninitial stress.

\subsection{Results}

\subsubsection{The Two-Syllable Window}

Overall a total of 2,230 words containing a single stress mark were found in the examined texts. Strikingly, 2,020 (91\%) of these words position stress on one of the first two syllables. Only $157(7 \%)$ words had stress on the third syllable, and $52(2 \%)$ had stress on a syllable after the third one. A similar preference for stress

\footnotetext{
${ }^{1}$ Words with multiple stresses are rare enough that no reliable inferences about the possibility of secondary stress are possible (see section 3.2.3 for further discussion of secondary stress).
} 


\section{An Intergenerational Study of Hupa Stress}

on one of the first two syllables was observed for all four narrators: Sam Brown (1,152 of 1,268 words have stress on one of first two syllables), Emma Frank (297 of 324), Jake Hostler (486 of 544), and John Shoemaker (76 of 87). Examples of stress falling on the first, second, and later syllables appear in (1). Hyphens separate roots from a following enclitic. The text and the line number for each example are in parentheses. Translations are from Golla and O'Neill (2001).

\section{(1)}

\author{
Initial stress \\ ts ámehstł'o:n \\ xóntah \\ t'ó:-te'in? \\ Peninitial stress \\ xotá:ja?kj'e?e?il \\ мixé:q'e? \\ $\mathrm{k}^{\mathrm{j}}$ 'ohqît-ne?
}

Stress after 2nd syllable

naitehstijaj

mil-xotárja?e?il

miq'o?ohtine: 'woman'

Emma Frank's method of doctoring 34

'house'

The origin of the Misq'id Jump Dance 13

'to the river'

The village that blasphemed 4

'They swim down the river'

The village that blasphemed 5

'Spit of mine'

Emma Frank's method of doctoring 40

'Ye must pound acorns'

Power over the grizzly bear 5

'He went back home'

The hated suitor 24

'With it they swim downstream'

The village that blasphemed 6

'Help me (ye)!'

The hated suitor 44

The heavy preference for placing stress on one of the first two syllables cannot be attributed to a preponderance of disyllabic words in Hupa, since over $75 \%(1,680$ of 2,230$)$ of the words in the database have at least three syllables. Hupa words characteristically consist of a monosyllabic root preceded by one or more prefixes and optionally one or more enclitics. The strong tendency to confine stress to one of the first two syllables thus means that roots are often unstressed. This does not imply, however, that there is an active avoidance of root stress. Indeed there are several instances of stressed roots in the database where other phonological factors such as the two-syllable window and syllable weight effects (see section 3.2.2) would independently predict stress on the root. Examples of root stress in (1) include [k' acorns' and [\{thó: $\}$ t $\int^{\prime}$ in?] 'to the river'. Rather, it suggests that stress in Hupa was largely blind to morphological structure at the time of Sapir's work. The twosyllable window is also consistent with Golla's (1970) description of prominence declination, which implies stronger stress closer to the left edge of a word. 
Matthew Gordon and Edmundo Luna

\subsubsection{Syllable Weight}

Within the two-syllable window at the left edge of a word, the location of stress is largely predictable with two factors being relevant. First, there is a preference for initial stress over second-syllable stress, all else being equal. Second, the likelihood of attracting stress is a function of syllable weight, where weight adheres to a four-level hierarchy. Long vowels are heaviest (CVV), followed by syllables containing a short vowel and a coda other than $/ \mathrm{h} /$ or glottal stop (CVC), followed by open syllables containing a short vowel (CV), followed by syllables closed by a glottal (either glottal stop or $/ \mathrm{h} /)(\mathrm{CVH})$ : $\mathrm{CVV}>\mathrm{CVC}>\mathrm{CV}>\mathrm{CVH}$.

This hierarchy interacts with the preference for initial stress to produce a continuum of likelihood of initial stress over second-syllable stress. The greater the weight of the first syllable relative to the second syllable, the greater the skewing toward initial stress. Conversely, the tendency for initial stress decreases as the weight of the first syllable diminishes relative to the second syllable. Thus the likelihood of initial stress is highest when the first syllable is CVV and the second is $\mathrm{CVH}$, while initial stress is least likely when the first syllable is $\mathrm{CVH}$ and the second is CVV. When the first two syllables are equivalent in weight, stress favors the initial syllable. Example words illustrating the preference for initial stress and the relevance of syllable weight appear in (2).

\begin{tabular}{|c|c|c|}
\hline $\mathrm{CVV}>\mathrm{CVC}$ & q'ant J'ú:ltt ${ }^{\mathrm{w}} \mathrm{il}$ & $\begin{array}{l}\text { 'a young man' } \\
\text { A war btn the Hupa and Yurok } 56\end{array}$ \\
\hline $\mathrm{CVV}>\mathrm{CV}$ & xotá:ja?kj'e?e?il & $\begin{array}{l}\text { 'They swim down the river' } \\
\text { The village that blasphemed } 5\end{array}$ \\
\hline $\mathrm{CVV}>\mathrm{CVH}$ & jehjá:kj’itiltal & $\begin{array}{l}\text { 'Let us go in stamp-dancing' } \\
\text { The Kick Dance } 38\end{array}$ \\
\hline $\mathrm{CVC}>\mathrm{CV}$ & $\mathrm{k}^{\mathrm{j}}$ 'e?ilxiw-mil & $\begin{array}{l}\text { 'When she's finished' } \\
\text { The Kick Dance } 26\end{array}$ \\
\hline $\mathrm{CVC}>\mathrm{CVH}$ & me?nîlk $k^{\mathrm{jit}}$ & $\begin{array}{l}\text { 'He fears it' } \\
\text { Power over the grizzly bear } 57\end{array}$ \\
\hline $\mathrm{CV}>\mathrm{CVH}$ & naPk ${ }^{\mathrm{j}} \hat{1}^{\mathrm{i}} \mathrm{h}^{\mathrm{h}}$ ?a?aw & $\begin{array}{l}\text { 'again starts singing' } \\
\text { The Kick Dance } 35\end{array}$ \\
\hline Initial in tie & tánlayмo?-tin & $\begin{array}{l}\text { 'several times' } \\
\text { The Kick Dance } 15\end{array}$ \\
\hline
\end{tabular}

Table 1 provides the number of words with initial stress and the number of words with second-syllable stress as a function of the weight of the initial (x-axis) and second (y-axis) syllables. The percentage of words with initial stress appears in parentheses. The number of cases of initial stress appears before the slash and the number of cases of peninitial stress comes after the slash. As Table 1 shows, there is an increasing tendency toward initial stress as the weight of the first syllable increases relative to the second syllable, i.e., as one moves down and to the right of the table. For example, only $9 \%$ of the words with a CVV second syllable after a $\mathrm{CVH}$ initial have initial stress. When, however, the first syllable is CVV and the 


\section{An Intergenerational Study of Hupa Stress}

second is $\mathrm{CVH}, 99.2 \%$ of words have initial stress. The bias for initial stress is evident when the first two syllables are equal in weight, in which case stress falls on the first syllable greater than half the time with the likelihood of initial stress increasing (roughly) as a function of the weight of the first two syllables.

\subsubsection{The Role of Weight in Stress to the Right of the Two-Syllable Window}

The relevance of weight in the first two syllables raises the question of whether instances of stress occurring after the first two syllables might be attributed to a weight effect. Thus stress might fall to the right of the two-syllable window if a syllable outside of the window is heavier than either of the first two syllables. For example, we might ask whether a CVV third syllable tends to attract stress from an initial CV.CV sequence due to its heavier status. For this to be established, two facts must be demonstrated. First, one must show that, in words with thirdsyllable stress, the third syllable tends to be heavier than the first two. Second, it must be established that, in words with stress on one of the first two syllables, there is not a heavier syllable after the second syllable.

Table 1. Number of words with initial or peninitial stress as a function of weight

\section{Initial syllable}

\begin{tabular}{|c|c|c|c|c|}
\hline & CVH & $\mathrm{CV}$ & CVC & CVV \\
\hline CVV & $\begin{array}{l}8.5 / 85.5 \\
(9.0 \%)\end{array}$ & $\begin{array}{l}54 / 168 \\
(44.3 \%)\end{array}$ & $\begin{array}{l}39.8 / 60.2 \\
(39.8 \%)\end{array}$ & $\begin{array}{l}164.5 / 28.5 \\
(85.2 \%)\end{array}$ \\
\hline CVC & $\begin{array}{l}27.3 / 74.8 \\
(26.7 \%)\end{array}$ & $\begin{array}{l}142.5 / 107.5 \\
(57 \%)\end{array}$ & $\begin{array}{l}88 / 23 \\
(79.3 \%)\end{array}$ & $\begin{array}{l}157.8 / 11.2 \\
(93.4 \%)\end{array}$ \\
\hline $\mathrm{CV}$ & $\begin{array}{l}31 / 48 \\
(39.2 \%)\end{array}$ & $\begin{array}{l}64.9 / 39.3 \\
(62.3 \%)\end{array}$ & $\begin{array}{l}31 / 5 \\
(86.1 \%)\end{array}$ & $\begin{array}{l}157 / 4 \\
(97.5 \%)\end{array}$ \\
\hline $\mathrm{CVH}$ & $\begin{array}{l}9.5 / 5.5 \\
(63.3 \%)\end{array}$ & $\begin{array}{l}116.7 / 17.3 \\
(87.1 \%)\end{array}$ & $\begin{array}{l}81 / 15 \\
(84.4 \%)\end{array}$ & $\begin{array}{l}152.8 / 1.2 \\
(99.2 \%)\end{array}$ \\
\hline
\end{tabular}

The hypothesis that stress migration to the right of the two-syllable window is a weight effect was tested against a subset of the data (12 of the 18 stories). For these stories, there were a total of 99 tokens with stress on the third syllable. Of these 99 words, the third syllable was CVV in 51, CVC in 24, and CV or CVH in 24. Of the 51 words with stress on a CVV third syllable, 46 lacked a CVV syllable among the first two syllables. Of the 24 with stress on a CVC third syllable, 16 lacked a heavier or equivalently heavy syllable, i.e., CVV or CVC, among the first two. Based on these data, it might seem that weight is responsible for stress falling to the right of the second syllable. However, of the 24 words with stress on a $\mathrm{CV}$ or $\mathrm{CVH}$ third syllable, 18 have a syllable at least as heavy as $\mathrm{CV}$ among the first two. This result argues against the hypothesis that stress only tends to drift to the right of the first two syllables if there is a heavier syllable after the second syllable. More tellingly, 132 words in the corpus have stress on a 
Matthew Gordon and Edmundo Luna

non-CVV syllable within the two-syllable window despite having a CVV syllable to the right of the window. This figure far exceeds the 46 words with stress on a CVV third syllable and no CVV syllable among the first two. We may thus conclude that while many cases of stress to the right of the two-syllable window are consistent with a preference for placing stress on heavy syllables, stress is not consistently attracted by heavy syllables outside of the window.

\subsubsection{Summary of Patterns in Hupa in Sapir's Texts}

In summary, Sapir's transcriptions suggest a strong tendency to restrict stress to one of the first two syllables in a word without any preference for stressing roots over affixes. Within the two-syllable stress window at the left edge of a word, initial stress is preferred, although this preference weakens as the weight of the second syllable increases relative to the weight of the first syllable. Syllable weight operates along a four-way weight hierarchy: $\mathrm{CVV}>\mathrm{CVC}>\mathrm{CV}>\mathrm{CVH}$. Most of the isolated cases of stress falling outside of the first two syllables of a word involve a heavy syllable attracting stress away from lighter syllables within the two-syllable window. Nevertheless, the attraction of stress by a syllable outside of the first two is a relatively rare phenomenon regardless of weight.

\section{An Acoustic and Phonological Study of Modern Hupa \\ 3.1. Methodology}

An analysis of stress was conducted based on approximately 100 words elicited in isolation by two Hupa speakers in 1995 and on a shorter list of approximately 25 words uttered by a third speaker. Most of the words were recorded onto a high quality portable analog cassette recorded using a noise cancelling unidirectional microphone. The recorded words ranged from two to seven syllables long and differed in their morphological composition and the structure of syllables comprising the word. In addition, for two of the speakers, stress patterns were transcribed for a smaller set of words not recorded. Recorded data were digitized at $16 \mathrm{kHz}$ using Kay Elemetrics CSL and acoustic analysis was performed using Scicon's MacQuirer. Three measurements were taken for each of the syllables in the word. First, the duration of each vowel was measured from a waveform in conjunction with a spectrogram. Second, intensity was measured at the mid point of each vowel from an intensity curve. Finally, the fundamental frequency value at the mid point of each vowel was taken from a pitch trace.

\subsection{Results of the Acoustic/Phonological Study}

Based on the examined data, two factors are relevant for predicting the location of stress in modern Hupa: syllable weight and morphological structure.

\subsubsection{The Role of Syllable Weight in Modern Hupa Stress}

Impressionistic transcriptions of stress and acoustic measurements point to the preferential attraction of stress by long vocoids, including long vowels and vowels followed by a glide. The corpus includes many words containing a single long 
vocoid, which consistently attracts stress over other syllables regardless of position. Words illustrating the attraction of stress by long vocoids appear in (3).

\begin{tabular}{|c|c|c|c|}
\hline 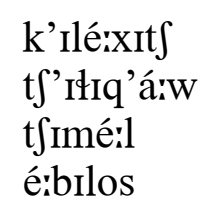 & $\begin{array}{l}\text { 'boy' } \\
\text { 'he's fat' } \\
\text { 'lizard' } \\
\text { 'apple' }\end{array}$ & 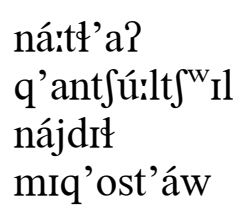 & $\begin{array}{l}\text { 'backwards' } \\
\text { 'teenage boy' } \\
\text { 'we go about' } \\
\text { 'nine' }\end{array}$ \\
\hline
\end{tabular}

Acoustic results are consistent with the attraction of stress by long vocoids. For all three speakers, long vocoids have greater intensity and higher fundamental frequency than short vowels in words with a single long vowel. Results for intensity and $\mathrm{f} 0$ for the three speakers are depicted graphically in Figure 1. Pairwise comparisons for both intensity and f0 between short (unstressed) vowels and long (stressed) vowels reach statistical significance at minimally $p<0.05$ in unpaired t-tests for all speakers, except for M2, for whom the intensity difference failed to reach significance, likely due to the relatively small number of tokens.

Figure 1. Intensity (left) and fundamental frequency (right) of stressed (dark bars) and unstressed (light bars) vowels in words containing one long vowel. Asterisks mark statistically significant comparisons; error bars mark standard deviations.
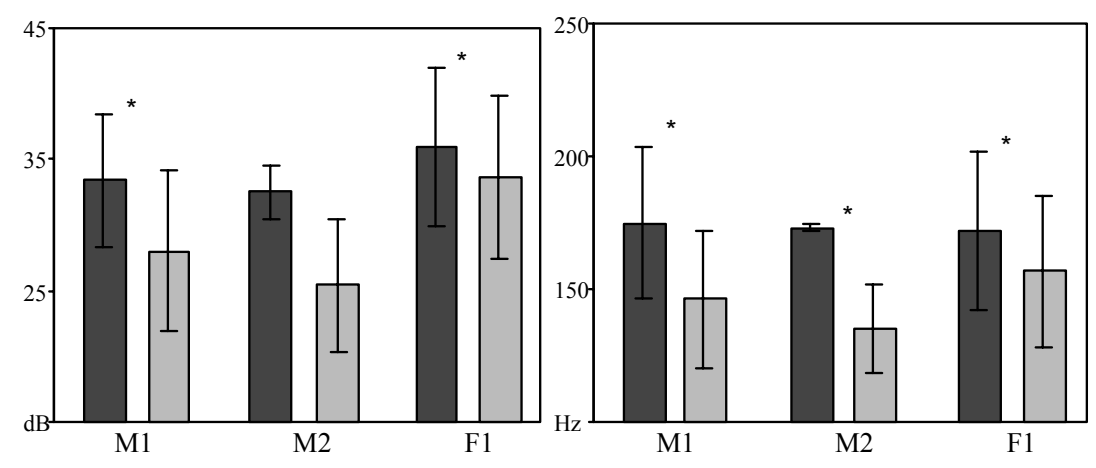

In words containing multiple long vocoids, the first long vocoid is more prominent than subsequent ones, as the examples in (4) show. ${ }^{2}$

$$
\begin{array}{llll}
\text { mé:ne:skit } & \text { 'I was afraid' } & \text { ná:jne:l } & \text { 'I played' } \\
\text { nó:k'me:jo:t } & \text { 'dog' } & \text { k'é:ne:s } & \text { 'it's tall' }
\end{array}
$$

Acoustic results generally line up well with these patterns though not all potential correlates of stress are used to cue stress in words with multiple long vowels. In

\footnotetext{
${ }^{2}$ There is one word in the corpus with an extra-long vocoid, i.e., a long vowel followed by a glide. In this word, [no:'na:wts ${ }^{\mathrm{h}} \mathrm{e}$ ] 'door', the extra-long vocoid attracts stress from an earlier long vowel.
} 
particular, duration does not reliably distinguish stressed and unstressed long vowels. Results by speaker are shown in Figure 2. Intensity and f0 reliably distinguish stressed and unstressed long vowels, with pairwise comparisons for individual speakers reaching significance in unpaired t-tests for the two male speakers but not for the female speaker. Nevertheless, the female speaker shows the same tendency for higher f0 on stressed long vowels as the male speakers, though this difference is not statistically reliable. Duration does not reliably distinguish stressed and unstressed long vowels. In fact, unstressed long vowels are longer than stressed long vowels for the second male speaker though this difference is not statistically reliable. It is likely that the greater length of unstressed long vowels is attributed to final lengthening, as some of the unstressed long vowels were in final position (see section 3.2.2).

\subsubsection{The Role of Morphology in Modern Hupa Stress}

In words lacking a long vowel, a preference for stressing roots over affixes rears its head. Most roots in Hupa, as in other Athabaskan languages, are monosyllabic. In words containing a monosyllabic root and lacking long vowels, stress falls on the root syllable, which is necessarily heavy due to a restriction requiring that roots end in a CVV or CVC syllable. Words illustrating root stress appear in (5).

Figure 2. Duration, intensity, and fundamental frequency of stressed (dark bars) and unstressed (light bars) vowels in words with more than one long vowel.
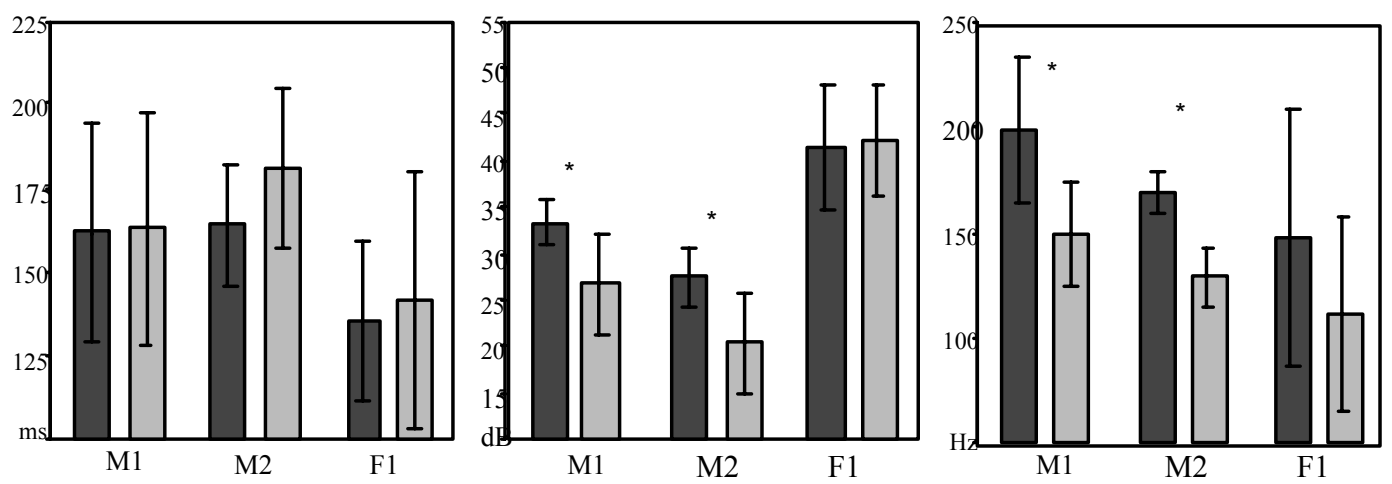

$$
\begin{aligned}
& \text { nI }\{\text { ty'its' }\} \quad \text { 'it's hard' } \operatorname{Mr}\{\mathrm{t} \text { 'án\}e? 'my apron' } \\
& \text { nI }\left\{\text { q'ós\} 'your neck' \{tínk }{ }^{j} \text { ' }\right\} \text { Itin 'four times' } \\
& \text { xo }\{t \text { t 'It }\} \quad \text { 'I know him' wum }\{\text { xít'\}ne?en 'I swallowed it' }
\end{aligned}
$$

Syllable weight interacts with the attraction of stress by roots in two cases. First, short voweled syllables closed by a glottal, either $/ \mathrm{h} /$ or glottal stop, optionally pass stress to the initial syllable even if this syllable is not part of the root. Thus, the words in (6) have two variants. 


$$
\begin{aligned}
& \text { Mí }\{\operatorname{ta} 9\} / \text { mI }\{\text { táP\} 'my mouth' ní }\{\mathrm{t} \text { 'ah }\} / \text { nI }\{\mathrm{t} \text { 'áh }\} \text { 'your pocket' }
\end{aligned}
$$

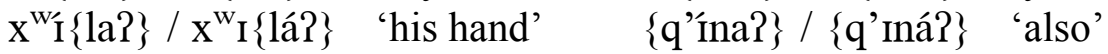

The second case in which weight interacts with morphology arises in polysyllabic roots. Such roots preferentially stress $\mathrm{CVC}$ over $\mathrm{CV}$, a preference that manifests itself in words lacking a CVV prefix. Thus in a polysyllabic root with a single $\mathrm{CVC}$ syllable and one or more $\mathrm{CV}$ syllables, the $\mathrm{CVC}$ syllable attracts stress. In polysyllabic roots with multiple CVC, the first one typically is stressed. Examples of stress patterns in polysyllabic roots without a long vowel are in (7).

$$
\begin{array}{llll}
\{\text { míntrtf\} } & \text { 'wildcat' } & \{\text { alás\} } & \text { 'nasty' } \\
\text { noh\{xóntah\} } & \text { 'our house' } & \{\text { tf'áhla?qate?\} } & \text { 'sunflower' } \\
\{\text { xóltfeh } & \text { 'skunk' } & \{\text { táhmine? } & \text { 'lichen' }
\end{array}
$$

Stressed short vowels typically have greater duration and intensity and higher f0 than unstressed short vowels in the same word, as Figure 3 shows.

Figure 3. Duration, intensity, and fundamental frequency of stressed (dark bars) and unstressed (light bars) short vowels in words lacking a long vowel.
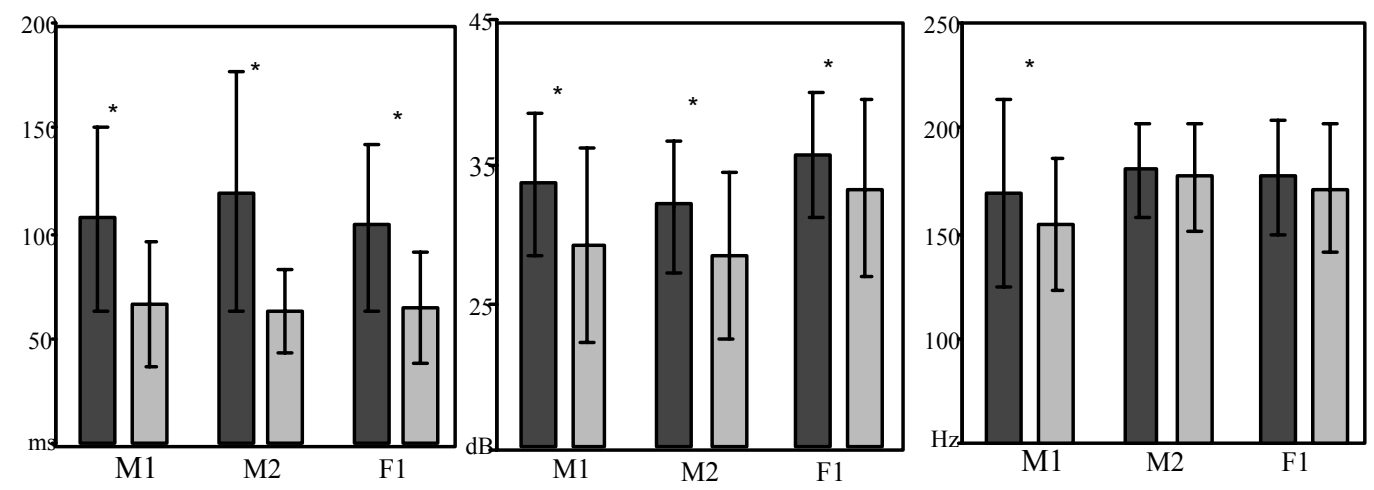

One question raised by the use of duration as a signal of root stress is the potential confounding factor of final lengthening, since most of the short stressed vowels are word-final. In order to assess this possibility, another duration analysis was conducted excluding vowels in final syllables. Results are shown in Figure 4 for the first male speaker and the female speaker, the two speakers for whom there was sufficient data to make the comparison. The duration difference between stressed short root vowels and unstressed non-final affixal vowels still obtains. The duration difference between stressed and unstressed vowels, however, is smaller. Thus, both stress and final position cause lengthening, a pattern also found by Tuttle (in press) in Apache, another Athabaskan language. 
Matthew Gordon and Edmundo Luna

Figure 4. Duration of stressed (dark bars) and unstressed (light bars) short vowels in non-final syllables.

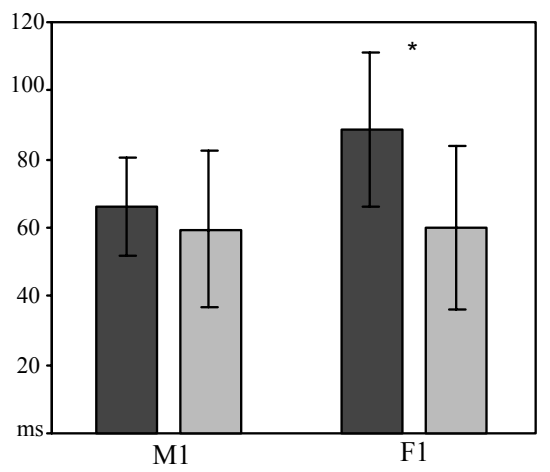

\subsubsection{Secondary Stress}

The examined data failed to show convincing evidence for secondary stress. While non-primary stressed long vowels were more intense than unstressed short vowels for the female speaker, this trend was not observed for either of the male speakers. Furthermore, f0 was actually lower for non-primary stressed long vowels relative to unstressed short vowels for the second male speaker and the female speaker, with the other male speaker showing virtually no difference in $\mathrm{f} 0$.

\section{Discussion}

\subsection{Comparison of Stress in Sapir's Hupa and Modern Hupa}

The stress patterns found in Sapir's texts and those discovered in the analysis of Hupa as spoken 68 years after Sapir's work are similar in certain respects but different in others. Both sources of data observe the weight hierarchy CVV > CVC $>$ CV $>$ CVH. In Sapir's data, this hierarchy is relevant within the twosyllable window at the left edge of a word. In the more recent data, different portions of the weight hierarchy are applicable in different contexts. CVV is heavier than other syllables throughout the word, as reflected in the ability of CVV to attract stress both in the root and in affixes. CVC is heavier than CV only within the root, since root $\mathrm{CVC}$ attracts stress from a $\mathrm{CV}$ syllable to its left but prefixal CVC does not. Finally, the light status of $\mathrm{CVH}$ relative to all other syllables is evident in the root, where CVH (a subset of CVC) optionally rejects stress in the root, the only context where $\mathrm{CVH}$ could be stressed. Also common to both data sources is a leftward attraction of stress. In Sapir's data the leftmost syllable bears stress if the first two syllables are equal in weight. In the later data, the leftmost CVV attracts stress over a CVV to its right. Likewise, the leftmost $\mathrm{CVC}$ in a root characteristically carries stress over another CVC to its right.

The distinction between $\mathrm{CVC}$ and $\mathrm{CV}$ in the root is one manifestation of the increased role of morphology in the more recent data. Whereas the stress system in Sapir's data is insensitive to the distinction between roots and affixes, the root is stress-attracting in the later data. In this newer data, a root syllable carries stress unless there is a prefixal CVV to the left of the root. The two-syllable window 


\section{An Intergenerational Study of Hupa Stress}

effect is thus no longer relevant in the recent data, being replaced with an attraction of stress by roots.

One possible explanation for the difference in stress patterns between the two data sources is attributed to a difference in the nature of the data. Sapir's data come from narratives while the later data are drawn from words uttered in isolation. It is conceivable that words in isolation have different prominence patterns from those uttered in connected speech. This hypothesis assumes that Sapir's transcriptions of stress are not based on re-eliciting individual words after hearing them in larger phrases. If Sapir were going back and listening to words individually for transcription purposes, then his stress transcriptions could also be based on words uttered in isolation, as in the later data. In this case, we would need to look elsewhere for an explanation of the differences in results.

Another more interesting possibility is that the difference in the two studies reflects a genuine difference between two prosodic stages in Hupa. Assuming this to be the case, we may tentatively speculate on how the two-syllable window effect could have been replaced by root-sensitive stress. One possibility is that final lengthening (section 3.2.2) has gradually attracted stress to final syllables. Because the root typically is word-final, final stress could easily be equated with root-final stress. In support of this hypothesis, non-final short vowels are phonetically short and often are completely elided, particularly in open syllables. Their short duration and potential to delete would make short vowels less suitable docking sites for stress. In contrast, words containing a prefinal long vowel would be less resistant to stress shift due to the inherently greater length of long vowels.

\subsection{Stress in Hupa and Elsewhere in Athabaskan}

Hupa shares with several other Athabaskan languages its attraction of stress by roots, including the Northern Athabaskan languages Tanana (Tuttle 1998), Ahtna (Kari 1990, Tuttle 2003), Tahltan (Alderete and Rob in press), Witsuwit'en and Fort Ware Sekani (Hargus in press), and in Hare Slave nouns (Rice 1989, 1990). Tuttle (in press) finds that roots also attract stress in the southern Athabaskan languages Western and Jicarilla Apache (see also McDonough 1999 on Navajo).

Syllable weight effects are also observed in other Athabaskan languages besides Hupa. In Tanana, all heavy syllables attract stress, where heavy syllables are closed syllables and those containing a full, i.e. long, vowel. Alderete and Rob (in press) report interesting weight effects in Tahltan that resemble those found in Hupa in certain respects. They find that, although primary stress typically falls on the root, there are certain forms in the corpus where a prefixal CVV syllable pulls stress off the root, a pattern analogous to that observed regularly in the synchronic Hupa data. Strikingly, they also find that $\mathrm{CV}(\mathrm{C}) \mathrm{CVC}$ root-final syllables in disyllabic roots show a deviation from the initial stress pattern found in $\mathrm{CVCV}$ disyllabic roots. $\mathrm{CV}(\mathrm{C}) \mathrm{CVC}$ roots place stress on a final $\mathrm{CVC}$, parallel to the attraction of stress by CVC within Hupa roots. Hargus (2001, in press) reports a four-way weight hierarchy for stress in Witsuwit'en with long vowels heaviest, followed by non-reduced short vowels, followed by closed syllables containing a 
reduced vowel, followed by open syllables containing a reduced vowel. Hargus (in press) also finds that vowel quality (but not the distinction between open and closed syllables) is relevant for stress in Fort Ware Sekani.

There is relatively little work on the acoustic correlates of stress in Athabaskan languages to which the present study can be compared. Tuttle (1998) finds that duration is the most reliable correlate of stress in Minto and Salcha Tanana, with $\mathrm{f0}$ and intensity playing a supporting role in Salcha but not reliably in Minto. As Tuttle suggests, the lesser role of f0 (and perhaps intensity which is often correlated with f0) in Minto plausibly finds a functional explanation: tone is used to signal morphological and lexical contrasts in Minto but not Salcha. This accords with Hargus' (in press) study of stress in Witsuwit'en and Fort Ware Sekani, in which she shows that non-tonal Witsuwit'en relies more on f0 to cue stress than tonal Fort Ware Sekani. For both languages, duration and intensity are the most reliable correlates of stress.

Compared to these northern Athabaskan languages, Hupa's correlates of stress are quite robust, as duration, fundamental frequency, and intensity are all used to mark stress. The clear acoustic presence of stress is perhaps not surprising, since Hupa, like other Pacific Coast Athabaskan languages, lacks lexical tone. Thus, fundamental frequency is free to be used as a marker of stress.

\section{Conclusions}

This paper has examined stress patterns from two different sources on Hupa corresponding to two different stages in the history of the language separated by 68 years. Both sets of data are sensitive to the same syllable weight hierarchy: CVV > $\mathrm{CVC}>\mathrm{CV}>\mathrm{CVH}$. This weight hierarchy is manifested in different ways during the two stages of Hupa. In the Sapir data, weight is relevant within a two-syllable window at the left edge of a word, with stress preferentially falling on the initial syllable if the first two syllables are equivalent in weight. In the more recent acoustic data, stress falls on the leftmost CVV syllable and on the root in the absence of any prefixal long vowels. Within the root, stress preferentially falls on the leftmost closed syllable. Syllables closed by a glottal optionally reject stress in any context unless there is no other syllable containing a non-glottal coda. Hupa at both stages examined in this paper shares with certain other Athabaskan languages its sensitivity to syllable weight in its stress system. Furthermore, the later data follow the tendency for root stress in Athabaskan languages.

\section{References}

Alderete, John and Tanya Rob. In press. A corpus-based approach to Tahltan stress. In S. Hargus and K. Rice, eds., Athabaskan Prosody. Amsterdam: Benjamins.

Goddard, Pliny Earle. 1928. Pitch accent in Hupa. University of California Publications in American Archaeology and Ethnology 23:333-338.

Golla, Victor. 1970. Hupa grammar. Ph.D. diss., UC Berkeley. 
Hargus, Sharon. 2001. Quality sensitive stress reconsidered. University of Washington Working Papers in Linguistics 20:25-56.

Hargus, Sharon. In press. Prosody in two Athabaskan languages of Northern British Columbia. In S. Hargus and K. Rice, eds., Athabaskan Prosody. Amsterdam: Benjamins.

Kari, James. 1990. Ahtna Athabaskan Dictionary. Fairbanks, Alaska: Alaska Native Language Center.

McDonough, Joyce. 1999. Tone in Navajo. Anthropological Linguistics 41:503541.

Rice, Keren. 1989. A Grammar of Slave. New York: Mouton.

Rice, Keren. 1990. Prosodic constituency in Hare (Athapaskan): Evidence for the foot. Lingua 82:201-245.

Sapir, Edward, and Victor Golla. 2001. Hupa texts, with notes and lexicon. In V. Golla and S. O'Neill, eds., Northwest California Linguistics [The Collected Works of Edward Sapir XIV], 19-1011. New York: Mouton.

Tuttle, Siri. 1998. Metrical and tonal structures in Tanana Athabaskan. Ph.D. diss., University of Washington.

Tuttle, Siri. 2003. Realizations of stress and intonation in an Ahtna text. Paper presented at the 2003 Annual Meeting of SSILA, Atlanta.

Tuttle, Siri. In press. Duration, intonation, and prominence in Apache. In S. Hargus and K. Rice, eds., Athabaskan Prosody. Amsterdam: Benjamins.

Woodward, Mary. 1964. Hupa phonemics. In W. Bright, ed., Studies in Californian Linguistics [UC Publications in Linguistics 34], 199-216.

Department of Linguistics

University of California

Santa Barbara, CA 93106

mgordon@linguistics.ucsb.edu

ecluna@umail.ucsb.edu 